\title{
Energy Retrofitting: The Technique to Reduce Carbon Emission
}

\author{
Rohit V Ambapkar ${ }^{1}$, Dr. K Ravi ${ }^{2}$ \\ ${ }^{1,2}$ Department of Civil Engineering, Ashokrao Mane Group of Institutions, Vathar, India
}

\begin{abstract}
Nowadays, there is remarkable enhancement in energy issues that are responsible for causing threats to the environment. These issues are generated due to growth in construction industry and ignorance of environmental aspects as well as carbon em ission. Various construction activities are carried out with enhanced features to greater extent. The building sector is also responsible for emitting carbon dioxide, greenhouse gases in huge amount and increase the occurrence of climatic change. Therefore to lessen carbon emission and to stop climatic change, there is need to use some advanced technique. In early days, buildings were designed by using traditional approaches which consumes huge energy and resources. Hence to reduce carbon emission of existing building, the study has been done which explores that there is need to use the retrofitting technique. Retrofitting is the process in which modification takes place after manufacturing. In terms of building, Retrofitting means that make changes towards the system inside the building or in part of the entire building after its initial construction and occupation. Retrofitting of existing buildings can help us to reduce the energy consumption as well as energy consumption will routinely reduce carbon emission.
\end{abstract}

Keywords: Construction industry, carbon emission, traditional approaches, retrofitting, energy consumption

\section{Introduction}

The growth of construction industry has resulted into tremendous rise in energy issues along with threats to environment. The major reason behind this is ignorance of environmental aspects and huge amount of carbon emission. Various construction activities such as construction of multiple sky-scrapers, buildings, roads, shopping malls etc are carried out with enhance features. Buildings are the fundamental part where energy consumption is more. Earlier buildings were designed by using traditional approaches which consumes huge energy and resources. Multiple residential buildings were constructed without integrating energy preservation techniques. This made energy issue to become a serious social problem.

The authors have done research [1] and stated that there is need to reduce $70 \%$ carbon emission till 2030 to diminish the climatic change. Lot of buildings (approximately 75\%) have already constructed and resulted into huge carbon emission. Therefore, it is required to refurbish the existing building based upon the low carbon emission techniques. Various technological interventions were carried out by using by building fabric, ventilation and appliances etc. on existing buildings. According to report of US, the total carbon dioxide (CO2) emissions from Residential and commercial buildings is almost 39 percent. All these greenhouse gas (GHG) emissions attributed to find alternate solution for controlling carbon emissions in housing as well as commercial sector.

Many buildings are constructed without formal design by qualified engineers and earlier than the opening of sustainability origin.

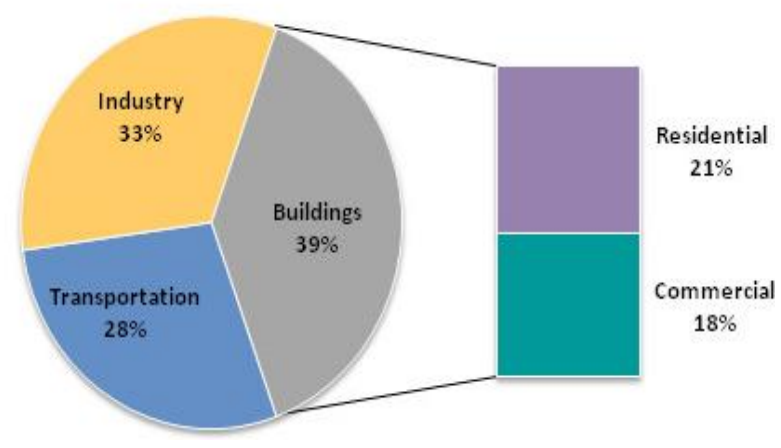

Figure 1: Buildings Share of U.S. Primary Energy Consumption (2006)

These buildings are primary consumer of energy and emitter of huge carbon. The author describes [3] that the existing buildings must undergo process of retrofitting. For dropping the energy utilize in buildings, the energy supplies of buildings should be minimized, the efficiency of energy use must be amplified and systems must be set up which sustain the use of sustainable energy sources. The energy competent envelop must be develop by using optical and thermo physical properties of envelop and various other techniques.

Building [4] is a sector where there can be a reduction in energy consumption and emission when the right technologies with energy efficient solutions are followed. New energy efficient technologies have been introduced which includes smart materials for faster development.

The author [5] discussed about the concept of retrofitting which is applied on existing building for the improvement energy performance. This improvement played significant role in reducing UK'S carbon reduction. But according to author, the problem is complex and difficult to deal as route to effectiveness is not clear yet. Lots of investment is needed to guarantee progressive saving. 


\section{International Journal of Science and Research (IJSR) \\ ISSN (Online): 2319-7064 \\ Index Copernicus Value (2013): 6.14 | Impact Factor (2014): 5.611}

Therefore, the study explores that there is need to go for process of retrofitting to reduce carbon emission of existing building. Retrofitting is the process in which modification takes place after manufacturing. Bringing this concept to building, this means that making changes to the system within the building or yet in part of the arrangement after its initial construction and occupation. Retrofitting of existing buildings can help us to reduce the energy consumption as well as energy consumption will routinely reduce carbon emission.

\section{Carbon Emission}

A carbon footprint consists of emission of carbon dioxide associated with an individual activity. It contains direct emissions such as emission occurred by car, any emission that consumes goods etc. it also includes emissions of some quantity of greenhouse gas. The final and critical effect of carbon footprints is Climate change. In United States, there is only $4 \%$ of population and they contribute to $25 \%$ of greenhouse gases. The major drawback of greenhouse gases is that they contribute in increasing the temperature of planet. Carbon dioxide emission has been increased by 31\% since 1990 to 2005 and further raised the level to 35\% in 2008 and so on. Due to huge accumulation of carbon footprints, resources are diminished. The deforestation activities have increased use of air conditioning appliances. More the use of appliances more is the generation of carbon footprint which results in huge amount of greenhouse gases and hence leads to climate change.

The cement industry is considered as one of the main producer of carbon dioxide and greenhouse gases. The concrete industry is also consider as one of the largest producers of $\mathrm{CO} 2$ which emits nearly $5 \%$ of man-made gases out of that $50 \%$ gas is released from chemical process and $40 \%$ is released from burning fuel. The concrete production produces carbon dioxide which is directly proportional to amount of cement content used in particular mixture. Approximately, foe every ton of cement, $900 \mathrm{~kg}$ of carbon dioxide is emitted.

Similarly, existing building sector is also responsible for emitting carbon dioxide, greenhouse gases at greater extent and increase the occurrence of climatic change. Thus the study says that there is need to lessen carbon dioxide emission in order to decrease climatic change. To reduce carbon footprint some steps must be followed.

1)There is needed to measure carbon foot print. Identification of source is necessary for understanding that is emitting carbon, at what extent and this data will be useful in reducing carbon.

2)Identify and apply measures to lessen carbon emissions. This can be done by modifying existing building into energy efficient building which results less carbon, using low carbon materials and moving towards the low carbon or renewable sources of energy.

3)Offsetting the remaining inescapable emissions which are associated with the particular sector or region.

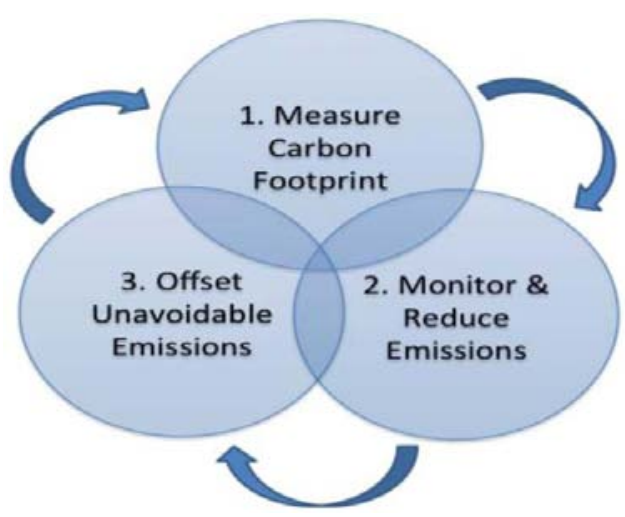

Figure 2: The carbon reduction procedure

The long term solution to lessen global warming is to reduce carbon emission generated by human activities. This can be done by building low carbon building or zero carbon building. It requires a careful planning. The term zero carbon or low carbon, is applied to the building that uses more renewable energy. This is done for new construction. But what happens if the building is already constructed? Now there is a need to look forward for retrofitting. Retrofitting technique is applies to existing building to reduce carbon emission.

\section{Building Operation}

Due to built-up growth, the quantity of buildings, lots of energy utilization, as well as the carbon emissions reaches to height in the nation. According to the 17th Electrical Power Survey (EPS) done by the Central Electricity Authority, demand for electricity is expected to increase by $39.7 \%$ in 2011-12 as compared to 2006-07, by another $43.7 \%$ in 2016 17 and another $37.5 \%$ expected rise in 2021-22. With a near consistent, there is $8 \%$ rise in annual energy consumption in both residential as well as commercial sectors. Henceforth, building energy consumption has seen an increase from 14\% in the 1970 s to nearly $33 \%$ in $2004-05$. Electricity which is used in residential and commercial sectors provides usage for lighting, space conditioning, household appliances such as refrigeration, water heating etc.

The rural residential sector mostly depends upon traditional non-commercial fuels. In India, as per 2001 Census, the electricity connection is established only in $43.5 \%$ of rural houses and more than $85 \%$ of electrified rural households use electricity for only lighting. For use of energy, urban sector rely on commercial fuels. In India, for commercial building sector approximately $60 \%$ of total electricity is consumed for lighting, $32 \%$ for space conditioning and $8 \%$ for refrigeration. For residential building, about $28 \%$ of the total electricity is consumed for lighting, $45 \%$ for the space conditioning, around $13 \%$ for refrigeration, nearly $4 \%$ for televisions and $10 \%$ for other appliances. In India for residential and commercial buildings, the average electricity consumption for lighting and space conditioning is about 160 $\mathrm{kWh} / \mathrm{m}^{2} /$ annum and $80 \mathrm{kWh} / \mathrm{m}^{2} / \mathrm{annum}$. The energy pattern of building varies with the climate of the region and building envelope. In a particular climate, energy usage varies from building to building depending on size, shape orientation, space, planning, envelope, design, choice of air conditioning 


\section{International Journal of Science and Research (IJSR) \\ ISSN (Online): 2319-7064 \\ Index Copernicus Value (2013): 6.14 | Impact Factor (2014): 5.611}

and lighting systems, operational and maintenance schedule, user's habits and so on.

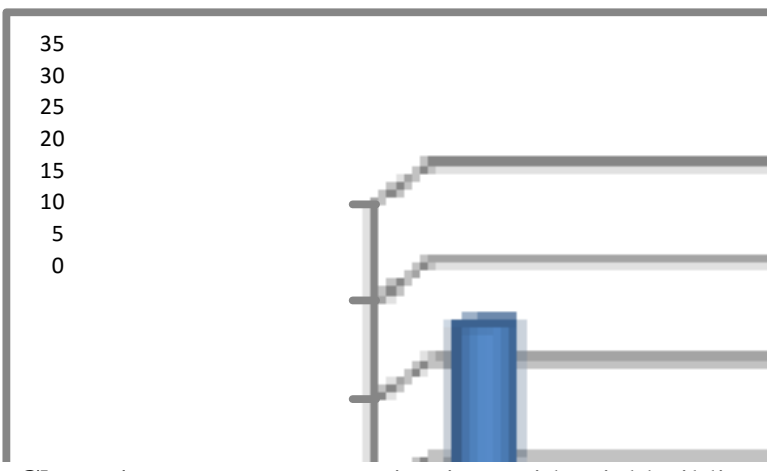

Chart 1: Energy consumption in Residential building

According to the scenario of Business As Usual (BAU) and concept of $10 \%$ annum raise in newly developed area, there would be 5.4 billion kWh boosts in electricity demand both in commercial and residential buildings. In Indian residential buildings, the energy consumption is expected to rise due to some factors such as economic growth, construction growth, human development etc. The demand for energy to run appliances such as, refrigerators', heating units, air conditioning, mobile phone chargers etc. also increases with greater extent as there is lot of improvements in living standards in India. As there is growth in commercial sector, people shift from rural area to urban area and continue living there. This results in considerable increase in total emissions from only building sectors. Hence, there is a need to take concerted efforts to decrease the energy consumption by buildings through various measures. The IPCC Fourth report states that there is need to take necessity approach to diminish carbon emissions from building sector. The comparative study on energy savings potential of the building sector and economic sectors has been done and it is observed that the building sector has highest prospective between all the sectors.

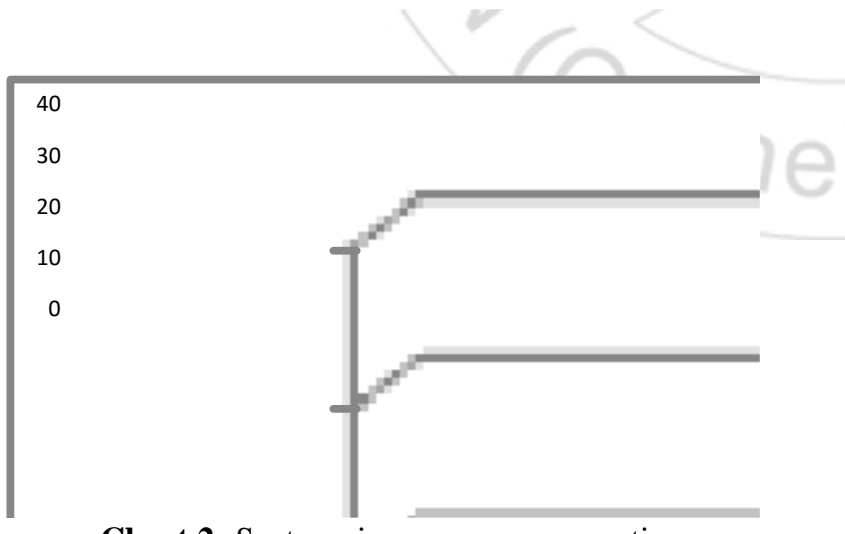

Chart 2: Sector wise energy consumption

\section{Need of Retrofitting}

Nowadays, multiple buildings are designed by considering the basis of sustainability. But before introducing the concept of sustainability, huge portion of the building was already built. These buildings were designed by considering traditional approach which consumes lots of energy and resources. Hence, there is a need to look forward towards new construction technique which benefits in all aspects. The energy efficient new construction techniques can be applied on these buildings so that they will prove to be important step towards sustainability. This means that the technique called retrofitting must be applied on existing buildings to produce ecological impact. Building envelope be termed like the boundary of energy loses as interacts directly with external environmental conditions. In order to reduce energy use energy requirements need to be reduced and effectiveness of energy use should be improved.

Retrofitting is the process in which modification takes place after manufacturing. Bringing this concept to building, this means that making changes to the systems inside the building or even the structure itself at some point after its initial construction and occupation. Energy retrofitting technique helps to reduce energy transfer and carbon emission to greater extent. With energy efficient retrofitting, buildings are able to obtain comfort conditions by minimum energy. The analysis of reduction in energy consumption and reducing the carbon emission of building by using green retrofitting technique will be done. There will also be rise in economic product by the decrease of energy consumption for heating, cooling, ventilation, lighting and hot water. In many of the retrofit projects, energy efficient retrofit strategies are not applied due to a lack of knowledge about the amount of investment required and the efficiency of the potential energy saving strategies. For a building to be retrofitted, interventions usually involve: roof, windows, walls and over cladding systems.

\section{Conclusion}

Through various studies it has been observed that there is a wide scope for research work in the area of advance construction and methods. Building energy is consumed for heating, cooling, lighting and ventilation of the buildings which forms direct interaction with the external environment conditions. For sinking the energy consumption in buildings, the energy necessities of buildings should be reduced and the efficiency of energy utilization should be improved with the help of advance energy retrofitting technique so that carbon emission through the building will get reduced. Hence, there is need of advanced technique like retrofitting to lessen carbon emission. This retrofitting technique can be applied on any kind of existing building such as residential building or sky-scrappers etc.

\section{References}

[1] Peacock, P.F.Banfill,"Reducing CO2 Emissions through Refurbishment of Non-Domestic UKk Buildings", 2005.

[2] Guillaume Fabre, "Low -Carbon Building -A method for estimating GHG emissions and emissions reduction, performance" Lulu publication 2009.

[3] Bahar Basarir, Berrin Sahin Diri and Cüneyt Diri, "Energy efficient retrofit methods at the building envelopes of the school buildings", 2011. 
[4] Sanja Vavan Vuceljic,"Application of smart materials in retrofitting homes can help housing energy efficiency", 2012.

[5] Dr. A Stafford,Prof. M. Bell,Prof. C.Gorse,"Building Confidence", March 2012.

[6] James Stepherd, "The Emergence of "Low-Carbon Cities- in Post Industrial Urban China".

[7] Samuel Fankhauser, "A practitioner's guide to a lowcarbon economy: lessons from the UK",January 2012.

[8] Robina Hetherington, Robin Laney, Stephen Peake, "Zero and Low Carbon Buildings", IEEE conference 2010.

[9] Nilanjan Sengupta , "Use of cost-effective construction technologies in India to mitigate climate change", Current science, VOL. 94, NO. 1, 10 January 2008.

[10] Rohit V Ambapkar, "A Survey on- A Dive towards Low Carbon Building", IJAERD, Vol-2, Issue 1, January 2015.

[11] Yang Shen and JingSha Hua, "Effectiveness of energy retrofit methods in public buildings in China", Institute for building efficiency, March 2012.

[12] Nandish Kavani, Fagun Pathak, "Retrofitting of an existing building into a green building" IJRET volume 03 Issue 06, 2014.

[13] AES carbon survey, "AES carbon audit report", 2013. 